\section{The role of PCR in the diagnosis of dermatophytes in onychomycosis}

Heba Mohtady Ali ${ }^{1}$, Amani Nasar? Nissreen Elsayed Elbadawy ${ }^{1}$, Mayada Abdelhafiz ${ }^{2}$

1 Microbiology \& Immunology and Dermatology, Venerology \& Andrology.

2 Departments, Faculty of Medicine, Zagazig University-Egypt.

\section{Contact information:}

Aim: To address onychomycosis regarding clinical and laboratory findings, and investigate different laboratory methods used in the identification of dermatophytes implicated in onychomycosis; including conventional laboratory methods ( $\mathrm{KOH}$ preparation), culture and multiplex polymerase chain reaction (PCR).

Methods: This cross-section study included sixty-one (61) patients (82\% females and $18 \%$ males). All collected samples were investigated using microscopic examination and cultivation of samples. In addition, DNA extraction and PCR amplification were evaluated.

Results: After mycological study of 61 cases, we found that distal lateral subungual onychomycosis (DLSO) was the most common clinical type in our study. Also, the dermatophytes appeared to be the chief causative agent in onychomycosis (61\%). In addition, positive results were identified in $67.2 \%, 60.7 \%$ and $73.8 \%$ of the studied group using PCR, culture and, $\mathrm{KOH}$ direct microscopy, respectively. With respects to the results of PCR in the study, the sensitivity, specificity and accuracy were, $100 \%, 83.3 \%$ and $93.4 \%$ respectively.

Conclusion: PCR was a highly sensitive method for diagnosis of onychomycosis. The application of PCR technology directly to the clinical specimens will permit early and accurate diagnosis of onychomycosis, and leading to prompt initiation of specific antifungal therapy.

\section{Prof. Heba Mohtady Ali.}

Address: Medical Microbiology \& Immunology Department, Faculty of Medicine, Zagazig University, Egypt. Postal Address: App 31, Building 46, Group 32 , Madinaty, New Cairo, Egypt.

Tel: +201001747935 .

झ hebamohtady@hotmail.com; hmohtady@gmail.com

\title{
Keywords
}

Onychomycosis, Dermatophytes, PCR diagnosis, Egyptian Patients. 


\section{Introduction}

Onychomycosis refers to a fungal infection that affects the toenails or the fingernails [1]. In clinical practice, it is the most commonly encountered nail disorder. Onychomycosis of the finger and toe nails affects approximately $5.5 \%$ of the world's population. It results in local pain,paraesthesia, diminished social interactions and quality of life [2]. Treatment of onychomycosis requires expensive and long-term therapeutic regimens with low cure rates and high relapse rates potential side effects. Therefore, a proper diagnosis of infection is needed [3-4].

Onychomycosis is most commonly caused by dermatophytes. These hyaline septated moulds such as Tinea rubrum and Tinea mentagrophytes are the main causative pathogens responsible for $80-90 \%$ of cases (about $90 \%$ of cases of toe nail onychomycosis and at least $50 \%$ of finger nail onychomycosis). However, Candida species and Non-Dermatophyte Moulds (NDMs) have also been implicated. Dermatophytes account for [5]. NDMs such as Acremonium species, Alternaria species, AspergiIlus species, Fusarium species, Scytalidium species and Scopulariopsis species have been found to be involved in 2-11\% of the onychomycosis cases reported. Yeasts, including Candida species, account for $2-10 \%$ of fungal nail infections [6].

Clinically, Onychomycosis is commonly classified as distal lateral subungual onychomycosis (DLSO), superficial white onychomycosis (SWO), proximal subungual onychomycosis (PSO) and total dystrophy (TD) based on the pattern and the site of infection involving the nail complex [7]. In DLSO, the invasion begins at the hyponychium and disturbs the distal nail bed; and spreads gradually to the matrix from distal to proximal with subungual hyperkeratosis and yellowish discoloration. However, in PSO, it affects the skin of the proximal nail fold, the cuticle and progressing along the eponychium (epithelium of the underside of the proximal nail fold). In this type, the fungi invade the nail plate from the matrix and proliferate distally within the nail plate. Other clinical forms include (SWO), where the upper surface of the nail plate is first attacked; (TD), which describes total nail plate involvement and surrounding periungual tissue; and endoynx, which describes distal nail plate attack resulting in a deeper penetration of hyphae [8-9].

Laboratory diagnosis of onychomycosis relies on proper sampling of the nail and demonstration of hyphae by direct microscopic examination after treatment with $\mathrm{KOH}$, followed by culture and species identification [10]. Direct microscopic examination of nail material is often adequate for the diagnosis of a fungal infection. It is considered as simple, rapid and cost-effective method. However, it does not provide genus or species identification and also it may give false-negative results [11].

Conventionally, a definitive diagnosis depends on culture isolation. Nevertheless, the culture is negative in up to $20 \%$ of the microscopy-positive cases and is time-consuming due to the slow growth (3 to 4 weeks) and sporulation of the causative organisms and the need for additional physiological tests [10-12].

Traditionally, $\mathrm{KOH}$ direct smear and fungal culture have been the preferred methods for the diagnosis of onychomycosis. Culture is considered the gold standard, while histopathology is often performed to diagnose and differentiate onychomycosis from other nail disorders such as psoriasis and lichen planus $[9,13]$.

Molecular tests such as PCR and Real-time PCR can be used for diagnosis of various microorganisms including fungal pathogens [14, 15]. The application of a two-step, 15-minute procedure for extraction of DNA directly from nail specimens and a multiplex PCR-based diagnosis of any dermatophyte and/or tinea rubrum with increased sensitivity compared to conventional diagnostic procedures allow integration of a molecular biology-based method into the routine examination of nail dermatophytosis and also for diagnostic laboratories receiving specimens on a larger scale $[9,16]$. 
This study aimed to address onychomycosis regarding clinical and laboratory findings. And, it aimed to investigate different laboratory methods used in the identification of dermatophytes implicated in onychomycosis; including conventional laboratory methods ( $\mathrm{KOH}$ preparation), culture and PCR.

\section{Materials and Methods}

\section{Study design}

This cross -section study included 61 patients with abnormal nails; for more than 12 months. This work was carried out in outpatient Dermatology and Andrology clinic and Microbiology and Immunology department; Faculty of Medicine in Zagazig university. The followings were the inclusion criteria after getting their consent agreement: patients more than 10 years old, having symptoms and signs suggesting onychomycosis and visiting outpatient Dermatology and Andrology clinic in Zagazig University. Diagnosis of onychomycosis caused by dermatophytes clinically; Primary criteria as white/ yellow or orange/brown patches or streaks and secondary criteria as onycholysis, subungual hyperkeratosis/debris, nail-plate thickening. The exclusive criteria included those who received topical or systemic antifungal treatment for at least four weeks, before sampling.

\section{Sample Collection and processing}

Ethyl alcohol (70\%) was applied to the nails of the subjects before the sample collection. Then, the finger nail clippings/scrapings/fragments were collected in a black envelope and they were sent to the laboratory for testing. The collected specimens were divided in to three portion [11].

The first portion of specimens were examined microscopically using $20 \% \mathrm{KOH}$. The specimen was mounted in a solution of $20 \mathrm{KOH}$ mixed with $5 \%$ glycerol, heated to emulsify lipids $(1 \mathrm{~h}$ at 51 to $\left.54^{\circ} \mathrm{C}\right)$, and examined under $\times 40$ magnification
[11]. In this first evaluation, negative samples were stored overnight in a humid chamber and examined again on the following day to confirm the result. The nail is examined for fungal hyphae, arthrospore or yeast forms. The second portion of nail specimen was crushed thoroughly to ensure fungal growth and cultured on: Sabouraud's dextrose agar (0.5\%) with dermasel supplement followed by microscopic examination of isolates $[11,17,18]$. Specimens were incubated at $25-30^{\circ} \mathrm{C}$. All plates were kept for a minimum of 2 weeks and absence of growth after 3-6 weeks was interpreted as negative. All the culture growths were identified on the basis of colony morphology and microscopical examination of lacto-phenol blue mounts [11].

The third portion of specimen was used in molecular detection of fungal DNA by PCR. Genomic DNA extraction form nail samples using fungal DNA preparation kit (i- genomic BYF DNA Extraction Mini kit, ThermoFisher Scientific, USA)[19]. Multiplex PCR was preformed using two pairs of pan dermatophyte primers targets the chitin synthase - encoding gene (chitin synthase 1- chs1) and served for detection of dermatophytes in general.; panDermal $15^{\prime}$ - GAAGAA-GATTGPCG TTT GCATCGTCTC-3' and pan Dermal 2 5' - CTCGAGG-TCAAAAGCACGC(AGAG-3'). In addition, T. rubrum - specific primer that targets internal transcribed spacer gene2 for the specific detection of $\mathrm{T}$. rubrum was also used (T. rubrum - for 5'- TCTTTGAACGCA-CATTGCGCC3'and T. rubrum - rev 5'- CGGTCCTGAGGGCGCTGAA-3') [20].

Agarose gel electrophoresis was done by conventional agarose gel electrophoresis [21]. The gel was then examined under the UV illuminator. Visualization of the bands between 300 and 400 bp in length (approximately 366 bp) recognizes pan-dermatophyte amplification product. In trichophytonrubrum specific PCR, amplification products were detected by visualization of the band approximately at 206 bp length. 


\section{Ethical consideration}

The study was approved by the Scientific Ethical Committee at the Faculty of Medicine, Zagazig University Hospital andan informed consent from each patient was obtained.

\section{Statistical Analysis}

Data were checked, entered and analyzed using SPSS version 19 for data processing. The following statistical methods were used for analysis of results of the present study. Data were expressed as number and percentage for qualitative variables. Chisquare test $(\mathrm{X} 2)$ was used to find the association between row and column variables. The agreement between different laboratory methods in measuring the same variable was estimated by Cohen's kappa test (K). Sensitivity, Specificity, Positive predictive value, Negative predictive value, Accuracy of different laboratory methods were determined. For all statistical tests done, the threshold of significance was fixed at $5 \%$ level (P-value).

\section{Results}

Sixty-one patients were enrolled in this study; all showed nail abnormalities clinically suggestive of onychomycosis. Regarding demographic data as shown in Table 1; their age ranged from 10 to 50 years and $54.1 \%$ of patients were from 30 to 49 years. Of these 61 patients, 50 (82\%) were females and $11(18 \%)$ were males. In addition, $65.6 \%$ of patients were from rural residents and $50.8 \%$ were house wives.

Based on clinical examination, there were 46 cases of fingernail abnormalities, 4 cases of toenail abnormalities and 11 cases showed combined abnormalities of fingernail and toenail abnormalities. Distal and lateral subungual onychomycosis (DLSO) was the most common clinical types of onychomycosis represented $70 \%$ of total cases as shown in Table $\mathbf{2}$.

In the current study, mycological culture was chosen as the reference method (gold standard) to assess
Table 1. Demographic data of the studied group.

\begin{tabular}{|l|c|c|}
\multirow{2}{*}{\multicolumn{1}{c|}{ Variable }} & \multicolumn{2}{c}{$(\mathbf{n = 6 1 )}$} \\
\cline { 2 - 3 } & No & $\%$ \\
\hline Age & & \\
\hline $10 y$ & 1 & 1.6 \\
\hline $10-29 y$ & 18 & 29.5 \\
\hline $30-49 y$ & 33 & 54.1 \\
\hline$\geq 50 y$ & 9 & 14.8 \\
\hline Sex & & \\
\hline Male & 11 & 18 \\
\hline Female & 50 & 82 \\
\hline Residence & & \\
\hline Rural & 40 & 65.6 \\
\hline Urban & 21 & 34.4 \\
\hline Occupation & & \\
\hline House wife & 31 & 50.8 \\
\hline Student & 6 & 9.8 \\
\hline Farmer & 2 & 3.3 \\
\hline Clark & 12 & 19.7 \\
\hline Drivers & 1 & 1.6 \\
\hline Lab Tech & 1 & 1.6 \\
\hline Manual Worker & 2 & 3.3 \\
\hline Specialist & 6 & 9.8 \\
\hline
\end{tabular}

Table 2. Clinical findings among the studied group.

\begin{tabular}{|l|c|c|}
\multirow{2}{*}{\multicolumn{1}{c|}{ Variable }} & \multicolumn{2}{c|}{$(\mathbf{n = 6 1 )}$} \\
\cline { 2 - 3 } & No & $\%$ \\
\hline Site & & \\
\hline Finger Only & 47 & 77 \\
\hline Toe Only & 4 & 6.6 \\
\hline Both & 10 & 16.4 \\
\hline Type & & \\
\hline DLSO & 43 & 70.5 \\
\hline TDO & 15 & 24.6 \\
\hline WSD & 2 & 2.3 \\
\hline PSO & 1 & 1.6 \\
\hline
\end{tabular}


the performance of each test. Diagnosis of onychomycosis was based on at least one test was positive. Fungal culture demonstrated that $41(67.2 \%)$ cases were dermatophyte positive, while 20 (32.8\%) wasdermatophyte negative. As regard direct microscopy by $\mathrm{KOH}$ examination; 45 (73.8) nail samples were positive. Culture was positive only in 37 (60.71\%) of nail samples revealing different fungi. Pan-dermatophyte PCR was positive in 41 (67.2\%) nail samples, while $T$. Rubrum-specific PCR was positive in only 14 (12.9\%) nail samples as shown in Table 3. With respects to the results of PCR in the study; the sensitivity, specificity and accuracy were, 100\%, 83.3\% and 93.4\% respectively as shown in Table 4.

Table 3. Demographic data of the studied group.

\begin{tabular}{|c|c|c|c|c|c|}
\hline \multirow{2}{*}{ PCR } & \multicolumn{2}{|c|}{ Culture } & \multirow{2}{*}{ Total } & \multirow{2}{*}{ Карра } & \multirow{2}{*}{$\mathbf{P}$} \\
\hline & + ve & -ve & & & \\
\hline +ve & 37 & 4 & 41 & \multirow{3}{*}{0.86} & \multirow{3}{*}{$<0.001 * *$} \\
\hline -ve & 0 & 20 & 20 & & \\
\hline Total & 37 & 24 & 61 & & \\
\hline
\end{tabular}

Table 4. Validity of PCR in diagnosis of onychomycosis in comparison to culture as gold standard.

\begin{tabular}{|l|c|c|}
\hline \multirow{2}{*}{} & \multicolumn{3}{c}{ Variable } & \multicolumn{2}{c}{$(\mathbf{n = 6 1 )}$} \\
\cline { 2 - 3 } & No & $\%$ \\
\hline PCR & 20 & 32.8 \\
\hline -ve & 41 & 67.2 \\
\hline +ve & & \\
\hline Culture & 16 & 26.2 \\
\hline -ve & 45 & 73.8 \\
\hline +ve & & \\
\hline Direct smear & 16 & 26.2 \\
\hline -ve & 45 & 73.8 \\
\hline
\end{tabular}

\section{Discussion}

Onychomycosis is a major widespread problem in dermatology. It is considered a disease of civilization. And, it is characterized by extreme chronicity and resistance to therapy $[2,22-23]$. As regards age, in our study, onychomycosis incidence rates were the highest between 20 and 50 years and decreased in patients over the age of 60 years. The suggested predisposing factors of onychomycosis include increasing age, immuno-suppression, poor peripheral circulation, and trauma [24]. Based on literature, subject 's age was a strong risk factor for development of onychomycosis. These studies reported its occurrence in $20 \%$ of elderly persons (> 60 years old), and in $50 \%$ of those (> 70 years old) [24-26].

Our study included more female patients affected by onychomycosis. This may be since females are of high risk to develop onychomycosis due to frequent immersion of their hands in water, exposure to chemicals and other household activities. This could be furtherly explained if we consider that over $50 \%$ of subjects were house wives. The low incidence of onychomycosis in men in our study may be due to lower rate of patients visited our hospital [27]. Also in line with our results,, Brilhante et al., and Morales et al., found that male to female ratio was $1: 1.6$ and $1: 3$ respectively $[28,29]$. However, in other studies conducted in North America and India, onychomycosis infection was higher in males rather than the females which may be attributed to more exposing activities practicing by men. Such differences in results may be also attributed to the different geographical areas as well [23, 24].

The current study demonstrated a greater involvement of fingernails compared to toenails. This finding is comparable with studies conducted by Sen et al., and Souza et al., [23, 30]. The reason for the higher frequency of fungal infection of fingernails is probably because of the frequent immersion of the hand, in water or exposure to chemicals and trauma [31]. Also, the toe nail onychomycosis has lower incidence in Egypt than those in studies conducted 
in India. This may be attributed to open foot wear and lesser concern for appearance of feet and toe nails [32].

DLSO was the most common clinical type in our study, and the second common clinical presentation was TDO type which is comparable to the findings of Wang and Ching [33] and Aagrwalla et al., [34]. Other authors like Romano et al., [35] and Bonnifaz et al. [36] also reported DLSO as the predominant clinical form.

With respects to our results based on laboratory diagnosis of onychomycosis in this study. The number of positive samples for fungi by $20 \mathrm{X} \mathrm{KOH}$ microscopic examination were 45 (73.8\%) samples which was also in accordance with the results of Pontes et al. [37]. In addition, the percentage of positive samples by culture on SDA (60.7\%). was likeresultsdetected by Munir et al. [38], exceeding culture results detected by Brilhante et al., in Brazil [28]. There were 8 cases positive by $\mathrm{KOH}$ and negative by culture. The direct microscopic examination using $\mathrm{KOH}$ is considered efficient and quick test to detect fungal infection especially when conducted by skilled professionals. However, it cannot identify the specific pathogen and may give false positive results.

Only four samples were positive by PCR and negative by culture in our study. This may be due to insufficiency amount of DNA samples [28, 38]. It might be relevant that PCR method can detect the genome of the dead fungal cells which could not be grown by culture. In addition, four samples were PCR negative but positive by $\mathrm{KOH}$ examination. Also, it is important to include significant amount of samples in PCR assays despite the fact that the available nail samples may be scarce [39]. Therefore, false negative result of PCR could be due to this factor. In agreement with our study, Lawry et al., examined 69 collected nail specimens by PCR and culture. They found that PCR detected dermatophytes in 35 and culture in 28 of 38 samples that were classified as positive and the sensitivity of PCR test was (92\%) higher than in culture (73\%) [40].
In this study, the dermatophytes appeared to be the chief causative agent in onychomycosis (61\%) and $T$. rubrum was the most common organism in dermatophyte onychomycosis in 14 (38\%) of positive samples. According to Mugge et al., dermatophyte, yeast and NDM may cause onychomycosis [22]. However, dermatophytes appeared to be the main organisms capable of attaching to the nails and producing infection. They examined 5077 nail samples from 4177 patients and found that the majority of causative agents were dermatophytes (68\%) and Trichophyton species were associated with the most cases [22].

This study shows that PCR had $100 \%$ sensitivity, 83.3\% specificity, 93.4\% accuracy and 90.2\% PPV, whereas $\mathrm{KOH}$ had $83.8 \%$ sensitivity, $41.7 \%$ specificity, $67.2 \%$ accuracy and $68.9 \%$ PPV. These results results are similar to the results of Wisselinke et al., who has concluded that the sensitivity of the PCR was $97 \%$, and it has showed a significant increase in detection rate of dermatophytes in clinical samples compared to culture [41].

Several molecular methods for the detection and identification of dermatophytes from clinical samples have been developed. Major difficulties of PCR methods are that it required training, sophisticated equipment and standardization and it is also expensive [42]. On the other hand, it is not only sensitive, but also has the potential to decrease the time taken for the laboratory identification of pathogens that grow slowly or are difficult to culture. One of the important advantages of PCR technology is direct detection of fungi in the clinical specimens that would allow early and accurate identification of causative agents of onychomycosis. This would permit prompt and targeted initiation of antifungal therapy. The use of PCR is reliable and rapid method which can be done within 24 hours in contrast to the 21 days of incubation required for the isolation of dermatophytes by culture $[43,44]$. 


\section{Conclusion}

This study found -among the studied subjects- DLSO was the most common clinical type of onychomycosis, and the dermatophytes appeared to be the chief causative agent of onychomycosis (61\%). The application of PCR technology directly to the clinical specimens allowed early and accurate diagnosis of onychomycosis, leading to prompt initiation of antifungal therapy.

\section{References}

1. Ilkit M, Durdu M. Tinea pedis: the etiology and global epidemiology of a common fungal infection. Crit Rev Microbiol 2015; 41(3):374-88.

2. Lipner SR, Scher RK. Onychomycosis: J Am Acad Dermatol; 80(4):835-51.

3. Grover C, Khurana A. An update on treatment of onychomycosis. Mycoses. 2012; 55(6):541-51.

4. Yang EJ, Lipner SR. Pharmacy costs of medications for the treatment of onychomycosis in the United States. J Am Acad Dermatol 2019.

5. Elewski BE, Tosti A. Risk factors and comorbidities for onychomycosis: implications for treatment with topical therapy. J Clin Aesthet Dermatol 2015; 8(11):38.

6. Thomas J, Jacobson G, Narkowicz C, Peterson G, Burnet H, Sharpe $C$. Toenail onychomycosis: an important global disease burden. J Clin Pharm Therapeut 2010; 35(5):497-519.

7. Leelavathi M, Noorlaily M. Onychomycosis nailed. Malays Fam Physician 2014; 9(1):2.

8. Hay RJ, Baran R. Onychomycosis: a proposed revision of the clinical classification. Elsevier; 2011.

9. Singal A, Khanna D. Onychomycosis: Diagnosis and management. Indian J Dermatol Venereol Leprol 2011; 77(6):659-72.

10. Westerberg DP, Voyack MJ. Onychomycosis: Current trends in diagnosis and treatment. Am fam physician 2013; 88(11).

11. Jung M, Shim J, Lee J, Lee J, Yang J, Lee DY, et al. Comparison of diagnostic methods for onychomycosis, and proposal of a diagnostic algorithm. Clin Exp Dermatol 2015; 40(5):479-84.

12. Weinberg JM, Koestenblatt EK, Tutrone WD, Tishler HR, Najarian L. Comparison of diagnostic methods in the evaluation of onychomycosis. J Am Acad Dermatol 2003; 49(2):193-7.

13. Rajpar S, Abdullah A. Management of onychomycosis and awareness of guidelines among dermatologists. $\mathrm{Br} J$ Dermatol 2006; 155(5):1080-2.

14. Hay RJ, Jones RM. New molecular tools in the diagnosis of superficial fungal infections. Clin Dermatol 2010; 28(2):190-6.
15. Schena L, Nigro F, Ippolito A, Gallitelli D. Real-time quantitative PCR: a new technology to detect and study phytopathogenic and antagonistic fungi. Eur J Plant Pathol 2004; 110(9):893-908.

16. Wang HY, Kim H, Choi E, Lee H. Performance of the Real Fungus $\triangle$ ID kit based on multiplex RTQPCR assay for the rapid detection and identification of Trichophyton spp. and Microsporum spp. in clinical specimens with suspected dermatophyte infection. J Appl Microbiol 2016; 120(1):234-47.

17. Almuzaini AM, Osman SA, Saeed EM. An outbreak of dermatophytosis in camels (Camelus dromedaríus) at Qassim Region, Central of Saudi Arabia. J Appl Anim Res 2016; 44(1):126-9.

18. Tartor YH, El Damaty HM, Mahmmod YS. Diagnostic performance of molecular and conventional methods for identification of dermatophyte species from clinically infected Arabian horses in Egypt. Veter dermatol 2016; 27(5):401-e102.

19. Meireles TEF, Rocha MFG, Brilhante RSN, Cordeiro RdA, Sidrim JJC. Successive mycological nail tests for onychomycosis: a strategy to improve diagnosis efficiency. Braz J Infect Dis 2008; 12(4):333-7.

20. Spiliopoulou A, Bartzavali C, Jelastopulu E, Anastassiou ED, Christofidou M. Evaluation of a commercial PCR test for the diagnosis of dermatophyte nail infections. J Med Microbiol 2015; 64(1):25-31.

21. Li X-f, Wei T, Hong W, Hui C, Shen Y-n, Lv G-x, et al. Direct detection and differentiation of causative fungi of onychomycosis by multiplex polymerase chain reaction-based assay. Eur J Dermatol 2011; 21(1):37-42.

22. Mügge C, Haustein UF, Nenoff P. Causative agents of onychomycosis-a retrospective study. JDDG: J Deutsch Derm Gesell 2006; 4(3):218-28.

23. Sen A, Bhunia D, Datta P, Ray A, Banerjee P. A study of onychomycosis at a tertiary care hospital in Eastern Bihar. Indian J Dermatol 2018; 63(2):141-6.

24. Ghannoum M, Hajjeh R, Scher R, Konnikov N, Gupta A, Summerbell $R$, et al. A large-scale North American study of fungal isolates from nails: the frequency of onychomycosis, fungal distribution, and antifungal susceptibility patterns. J Am Acad Dermatol 2000; 43(4):641-8.

25. Qureshi N. Studying and Diagnosing the Main CausativeAgent of Onychomycosis through Laboratory Procedures. Inter J Multi Sci Eng 2012; 3(2):13-5.

26. Rafiq ANMI, Zakaria A, Khondker L, Khan MSI, Doulah S, Hazra SC. Clinico-mycological correlation in onychomycosis in a tertiary level hospital. J Pakistan Ass Dermatol 2016; 23(3):277-83.

27. Gelotar P, Vachhani S, Patel B, Makwana N. The prevalence of fungi in fingernail onychomycosis. JCDR 2013; 7(2):250.

28. Brilhante $R$, Cordeiro R, Medrano D, Rocha M, Monteiro A, Cavalcante $C$, et al. Onychomycosis in Ceará (Northeast Brazil): epidemiological and laboratory aspects. Memórias do Instituto Oswaldo Cruz 2005; 100(2):131-5. 
29. Morales-Cardona CA, Valbuena-Mesa MC, Alvarado Z, Solorzano-Amador A. Non dermatophyte mould onychomycosis: a clinical and epidemiological study at a dermatology referral centre in B ogota, C olombia. Mycoses 2014; 57(5):284-93.

30. Souza L, Fernandes O, Passos X, Costa C, Lemos J, Silva M. Epidemiological and mycological data of onychomycosis in Goiania, Brazil. Mycoses 2010; 53(1):68-71.

31. Jesudanam TM, Rao GRR, Lakshmi DJ, Kumari GR. Onychomycosis: A significant medical problem. Indian J Dermatol Venerol Leprol 2002; 68(6):326.

32. Ahmad M, Gupta S, Gupte S. A clinico-mycological study of onychomycosis. Egypt Dermatol Online J 2010; 6(4).

33. Agarwalla A, Agrawal S, Khanal B. Onychomycosis in eastern Nepal. Nepal Med Coll . 2006; 8(4):215-9.

34. Wang S, Chi C. Onychomycosis in Taiwan. Int J Clin Pract 2005; 59(8):906-11.

35. Bonifaz A, Cruz-Aguilar P, Ponce RM. Onychomycosis by molds. Report of 78 cases. Eur J Dermatol 2007; 17(1):70-2.

36. Romano C, Gianni C, Difonzo EM. Retrospective study of onychomycosis in Italy: 1985-2000. Mycoses 2005; 48(1):42-4.

37. Pontes Z, Lima OE, Oliveira N, Dos JS, Ramos AL, Carvalho M. Onychomycosis in João Pessoa City, Brazil. Rev Argent Microbiol 2002; 34(2):95-9.

38. Munir S, Ganaie F, Kumar B, Tewari R, Badakshaan S. Epidemiologic, Clinico-mycological aspects of fungal infections of skin and its appendages. J Evol Med Dent Sci 2014; 3(16):4212-9.

39. Verrier J, Verrier J, Monod M, Monod M. Diagnosis of Dermatophytosis Using Molecular Biology. Mycopathologia 2017; 182(1):193-202.

40. Lawry MA, Haneke E, Strobeck K, Martin S, Zimmer B, Romano PS. Methods for diagnosing onychomycosis: a comparative study and review of the literature. Arch Dermatol 2000; 136(9):1112-6.
41. Wisselink G, Van Zanten E, Kooistra-Smid A. Trapped in keratin; a comparison of dermatophyte detection in nail, skin and hair samples directly from clinical samples using culture and realtime PCR. J Microbiol Methods 2011; 85(1):62-6.

42. Arca E1, Saracli MA, Akar A, Yildiran ST, Kurumlu Z, Gur AR.Polymerase chain reaction in the diagnosis of onychomycosis. Eur J Dermatol 2004; 14(1):52-5.

43. Bagyalakshmi R, Senthilvelan B, Therese K, Murugusundram S, Madhavan H. Application of polymerase chain reaction (PCR) and PCR based restriction fragment length polymorphism for detection and identification of dermatophytes from dermatological specimens. Indian J Dermatol 2008; 53(1):15.

44. Kardjeva V, Summerbell R, Kantardjiev T, DevliotouPanagiotidou D, Sotiriou E, Gräser Y. Forty-eight-hour diagnosis of onychomycosis with subtyping of Trichophyton rubrum strains. J Clin Microbiol 2006; 44(4):1419-27.

\section{Publish in The International}

Arabic Journal of Antimicrobial Agents

The Journal is an open access peer-reviewed journal that publishes scientific papers about all aspects of antimicrobials. The journal will publish original research articles, reviews, brief reports and case reports dealing with basic and clinical antibacterial agents, antiviral, antiprotozoals, antituberculuous, antifungal and antihelminthes agents. All manuscripts must be prepared in English, and are subject to a rigorous and fair peer-review process. Accepted papers will immediately appear online. The journal aims to advance the knowledge, attitude and the research of chemotherapy in the Arabic world in cooperation with international, national scientific and public societies as well as research centers with similar aims and objectives. 